\title{
Retrospective Analysis of Intracranial Hemorrhages in the COVID-19 Pandemic
}

\author{
Gurkan BERIKOL ${ }^{1}$, Goksu BOZDERELI BERIKOL ${ }^{2}$, Halil DOGAN² \\ ${ }^{1}$ Taksim Training and Research Hospital, Department of Neurosurgery, Istanbul, Turkey \\ ${ }^{2}$ Istanbul Bakirkoy Dr. Sadi Konuk Training and Research Hospital, Department of Emergency Medicine, Istanbul, Turkey \\ Corresponding author: Gurkan BERIKOL dr.berikol@gmail.com
}

\section{ABSTRACT}

AIM: To identify the characteristics of patients admitted to the emergency department with intracranial hemorrhages in the era of the COVID-19 pandemic.

MATERIAL and METHODS: Seventy-eight patients with spontaneous intracranial bleeding who were admitted to emergency departments and treated in neurosurgery clinics between March 11, 2020, and September 11, 2020, were included in the study.

RESULTS: The most frequent symptom was the loss of consciousness (32.1\%), followed by headache (15.4\%), syncope (10.3\%), motor loss (9\%), and seizures (9\%). Antiaggregant and anticoagulant drug use were detected in $37.2 \%$ of the patients. Intraparenchymal hematoma was the most common type of intracranial hemorrhage (59\%). Viral pneumonia was detected in $52.6 \%$ of the patients in thorax CTs. Surgical treatment was applied to $23.1 \%$ of the patients. There was no significant difference between patients with pneumonia and patients without pneumonia in the treatment modalities or 30-day mortality.

CONCLUSION: In this study, we found that low Glasgow Coma Scores affected mortality and that mechanical ventilation needs are higher in ICH patients with COVID-19. Nevertheless, the treatment differences may not have affected the outcomes.

KEYWORDS: COVID-19, Intracranial hemorrhage, SARS-CoV-2

ABBREVIATIONS: AVM: Arteriovenous malformation, CAD: Coronary artery disease, CRF: Chronic renal failure, CT: Computed tomography, CVE: Cerebrovascular event, DM: Diabetes mellitus, GCS: Glasgow Coma Scale, HT: Hypertension, ICH: Intracranial hemorrhage

\section{INTRODUCTION}

I ntracranial hemorrhages (ICHs) constitute approximately $10-20 \%$ of all cerebrovascular diseases (CVDs) with high mortality and morbidity rates (12). According to the American Society of Cardiology Stroke group, $\mathrm{ICH}$ and subarachnoid hemorrhages (SAHs) are seen in $76 \%$ and $24 \%$ of all hemorrhagic strokes, respectively (5).

In addition to genetic factors, hypertension (HT), low triglycerides, and anticoagulant and antiaggregant drug use, the relationship between intracranial hemorrhages and viruses such as CMV, perinatal enterovirus, herpes virus, HIV, and coronavirus infections has been previously described in the literature $(1,2,5,11,26)$.
COVID-19 is a disease with a mortality rate of $6 \%$, which at this writing has affected nearly 3 million people worldwide. Although the COVID-19 epidemic affected approximately 110,000 people in our country, with early diagnosis, early treatment, and early isolation methods, the mortality rate was $2.4 \%$ of all total cases. Although the association of COVID-19 with thromboembolic events such as stroke in intensive care patients has been shown $(17,20)$, the cause and effect relationship between COVID-19 and ICH is unclear. In addition, there are cases reported in the literature with COVID-19 and ICH $(14,29,32)$. In the pathophysiology of ICH in COVID-19 patients, it is thought that it may be related to the passage of COVID-19 to the central nervous system through the nasal cavity membrane through the first cranial nerve 
olfactory receptors, and there are discussions that $\mathrm{ICH}$ may be a manifestation or complication of COVID-19 (20).

It has been shown that the emergency management of patients with $\mathrm{ICH}$ and their rapid access to emergency intervention, age, Glasgow Coma Scale scores, increased intracranial pressure, intraventricular hemorrhages, and antithrombotic use are the factors that affect 90 -day mortality $(5,11)$. ICH management includes different approaches in terms of conservative and surgical treatments (12), such as ventriculostomy or surgical evacuation of hematoma (11). Thus, avoiding delayed admissions and early intervention is essential, especially under pandemic conditions.

We aimed to identify the characteristics of the patients admitted to the emergency department with $\mathrm{ICH}$ during the COVID-19 pandemic. Our secondary aim is to analyze the factors that cause mortality and poor outcomes within diagnosing and managing ICH patients with COVID-19.

\section{MATERIAL and METHODS}

This was a multicenter observational retrospective cohort study conducted in two training and research hospitals. The data of the patients with ICHs (intraparenchymal hemorrhage, subarachnoid hemorrhage, subdural hemorrhage, and epidural hemorrhage) from March 11, 2020 (when the first COVID-19 case was announced in our country) to August 11, 2020 were collected.

Demographic characteristics (age and sex) of the patients, vital signs at the time of the emergency department (ED) visit (systolic blood pressure, pulse, body temperature, and oxygen saturation), presenting complaints, history and medications, leucocyte, lymphocyte, hemoglobin, platelets, CRP, $\mathrm{Na}$, and pCO2 levels and imaging findings (Chest $X$-ray and Computed tomography findings) and PCR test results, treatment, length of stay in the ED, duration of hospitalization and outcomes were recorded in an electronic database file.

The inclusion criteria were as follows: patients aged 18 years and over, who were diagnosed with spontaneous intracranial hemorrhages (intraparenchymal hemorrhage, subarachnoid hemorrhage, subdural hemorrhage, and epidural hemorrhage) in the ED; and who had at least one positive PCR result before or at admission. Patients with intracranial bleeding secondary to trauma, patients not examined for COVID-19 with PCR tests, patients diagnosed with bacterial pneumonia, and patients whose data were missing or inaccessible were excluded.

According to the typical appearance of COVID-19 pneumonia in the thorax CT, according to the RSNA, ACR, and STR consensus (9), the thorax CT findings of these patients were described as COVID-19-associated pneumonia. Nonpneumonia patients were defined as having negative thorax CT findings according to the same consensus.

Our primary outcome was to identify the patient characteristics associated with ICH and COVID-19; the secondary outcome was to examine the difference in treatment and mortality between patients with COVID-19 pneumonia and those without pneumonia.
This study was conducted under the permission of Turkish Ministry of Health (2020-05-06T18_48_14). Ethical approval of this study was obtained from Institutional Review Board (Decision No and Date: 2020-12-19 and 08.06.2020).

\section{Statistical Analysis}

SPSS ${ }^{\circledR}$ for Windows version 23.0 was used for statistical analysis. The mean, standard deviation, median, minimum and maximum values, and percentages were calculated. The distribution of the groups was determined using the Kolmogorov-Smirnov normality test. The difference between the independent groups in terms of numerical variables was examined by independent samples (Student's t-test) and the Mann-Whitney $U$ test. The difference between the groups in terms of mortality and treatment groups was analyzed with the chi-square test. Spearman or Pearson's test was used in the correlation analysis according to the distribution of the data. The level of significance was determined as $p<0.05$.

\section{RESULTS}

One hundred fifty-six patients admitted to the ED were diagnosed with intracranial hemorrhage between March 11, 2020 and August 11, 2020. In 99 patients with spontaneous $\mathrm{ICH}, 21$ patients without or negative SARS-CoV-2 polymerase chain reaction test (PCR) and no thorax CT examination were excluded from the study. Therefore, 78 patients were included in the analysis.

The mean age of the patients was $61.69 \pm 19.08$ (min 18; max 96) (Table I). Eighteen patients were under age 50 (23\%). Fortyfour of the patients were male, and 34 were female. The most common symptoms were loss of consciousness $(32.1 \%)$, followed by headache (15.4\%), syncope (10.3\%), motor loss $(9 \%)$, and seizure (9\%). Three patients had dyspnea, and one patient had diarrhea at the time of admission to the ED.

The most common comorbid diseases were HT (57.7\%), diabetes mellitus (DM) (20.5\%), previous cerebrovascular events (CVEs) (21.8\%), coronary artery disease (CAD) (19.2\%), chronic renal failure (CRF) (10.3\%) and malignancy (17.9\%). Other diseases were hypothyroidism, dementia, chronic obstructive pulmonary disease, epilepsy, rheumatoid arthritis, acquired immunodeficiency syndrome, and intracranial hemorrhage.

The rate of antithrombotic and anticoagulant use was $37.2 \%$. The most commonly used drugs were aspirin (\%62) and warfarin (24\%).

The percentage of patients who had a GCS of 8 and above was $76.9 \%$. Patients with GCS 15 represented $38.4 \%$ of all patients. The rate of intubated patients was $21.8 \%$.

Aphasia was present in $33(42.3 \%)$ patients. Abnormal pupillary findings were seen in $16.6 \%$ of the cases. Motor loss was present in $43.5 \%$ of the patients, and facial paralysis was present in 4 patients (10.2\%).

Intraparenchymal hematoma was the most common type of intracranial hemorrhage (59\%). Subdural hematoma and SAH rates were $23.1 \%$ and $17.9 \%$, respectively. The frontal lobe was involved in approximately half of the patients (46.2\%). 
Table I: Distribution of Demographic and Physiological Parameters $(n=78)$

\begin{tabular}{|c|c|c|c|c|}
\hline & Mean & Median & 95\% Confidence Interval & Min-Max \\
\hline \multicolumn{5}{|l|}{ Vital Signs } \\
\hline Systolic Blood Pressure (mmHg) & 151.72 & & $142.12-161.31$ & $55-250$ \\
\hline Heart rate* (/dk) & 93.36 & & $89.68-97.03$ & $50-135$ \\
\hline Saturation (\%) & 95.69 & 97 & $94.83-96.56$ & $82-100$ \\
\hline Temperature $\left({ }^{\circ} \mathrm{C}\right)$ & 36.268 & 36 & $36.125-36.410$ & $35.0-38.0$ \\
\hline \multicolumn{5}{|l|}{ Laboratory Findings } \\
\hline PTT & 18.915 & 14.45 & $14.723-23.108$ & $3.7-120.0$ \\
\hline \#Leucocyte* & 9.9497 & & $9.038-10.86$ & $1.08-21.66$ \\
\hline \#Lymphocyte & 5.8510 & 2.09 & $3.87-7.83$ & $.16-50.30$ \\
\hline Hemoglobin* & 12.331 & & $11.79-12.86$ & $5.7-17.8$ \\
\hline Platelet* & 221274.36 & & $201615.66-240933.06$ & $16000-514000$ \\
\hline C-Reactive Protein (mg/dl) & 26.64 & 9.5 & $16.86-36.43$ & $1-231$ \\
\hline $\mathrm{Na}(\mathrm{mg} / \mathrm{dl})$ & 138.10 & 138 & $137.05-139.15$ & $124-158$ \\
\hline pCO2 (mmHg) & 42.477 & 41.40 & $39.74-45.28$ & 19.7-108.0 \\
\hline
\end{tabular}

*Variables with normal distributions were analyzed with parametric tests.

Most hemorrhages were seen in the right hemisphere $(44.9 \%)$ and left hemisphere (41\%), and bilateral involvement was seen at $14.1 \%$ (Figure $1 A-D, 2 A-D)$. In $23.1 \%$ of the patients, the ventricles were involved.

The patients with positive thorax CT findings as typical appearances $(n=37)$ for COVID-19 pneumonia according to the RSNA, ACR, and STR consensus (8) were $47.4 \%$.

The surgical treatment rate was $23.1 \%$ for all patients. One patient died in the emergency service, one patient was discharged, and all the other patients were hospitalized. Considering the duration of stay in the emergency department, we found that for $60.3 \%$ of the patients, their stay in the emergency department ended within 6 hours, except for three patients who stayed in the emergency department for more than 24 hours. Patients with a hospital stay of less than one week constituted $75.6 \%$ of all patients. The 30 -day mortality rate was found to be $28.2 \%$.

\section{COVID-19 Pneumonia vs Non-pneumonia}

There was no significant difference in thorax CT findings by age, sex, presenting complaints, comorbid diseases, or antithrombotic/anticoagulant drug use (Table II). The vital signs did not differ between the COVID-19 pneumonia and non-pneumonia groups, but GCS was significantly lower $(59.5 \%$ vs. $40.5 \%)$ in the COVID-19 pneumonia group $(p=0.02)$ (Table II). Neurological examination findings did not differ between groups (Table II). The number of mechanically ventilated patients was significantly higher in COVID-19 pneumonia patients $(p=0.001)$. There was no significant difference between the regions or types of $\mathrm{ICHs}$, but ventricle involvement was significantly higher in the COVID-19 pneumonia group $(\mathrm{p}=0.003)$.

Although mortality and medical treatment choice were higher in pneumonia, no significant difference was found for either treatment or mortality between pneumonia and nonpneumonia patients (Table II).

\section{Mortality}

Age, sex, presenting complaints, vital signs, comorbidities, and antithrombotic/anticoagulant drugs did not differ in terms of mortality. GCS $\leq 8$ was significantly higher in the 30-day mortality group $(p=0.000)$. Lateralization was significantly lower in the mortality group $(p=0.029)$ (Table II). Mechanical ventilation was significantly higher in the mortality group $(p=0.000)$. There was no significant difference among the coagulation values, but platelets were significantly lower in the 

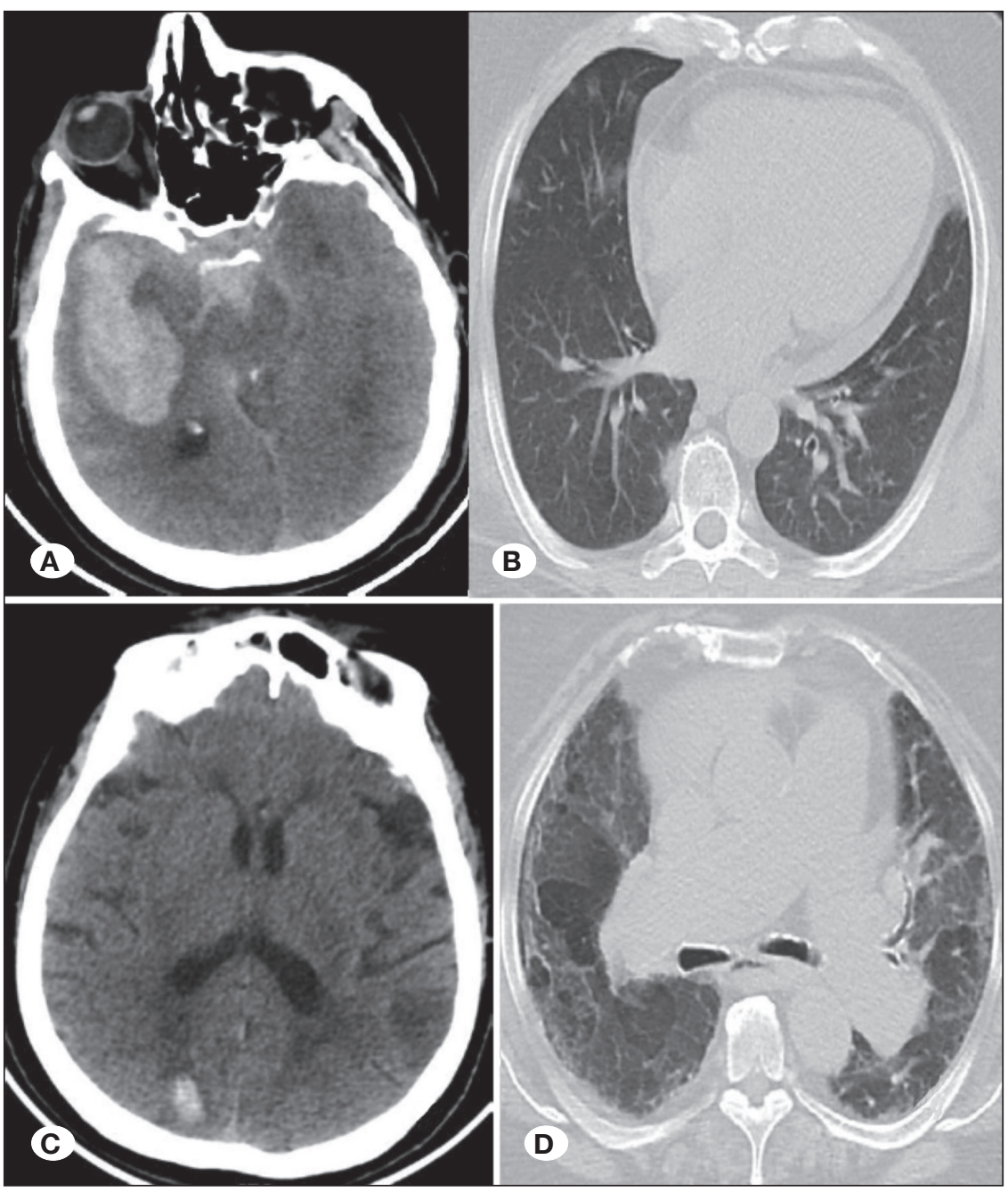

Figure 1: A) Cranial computed tomography (CT) scan showing a parenchymal hematoma in the right temporal region and subarachnoid hematoma in the prepontine cistern and sulci. B) Typical COVID-19 pneumonia with ground glass opacities in multifocal round morphology are observed in both lungs. C) Parenchymal hematoma in the right occipital region.

D) Multifocal mosaic attenuation appearance is seen in both lungs on chest CT scan.

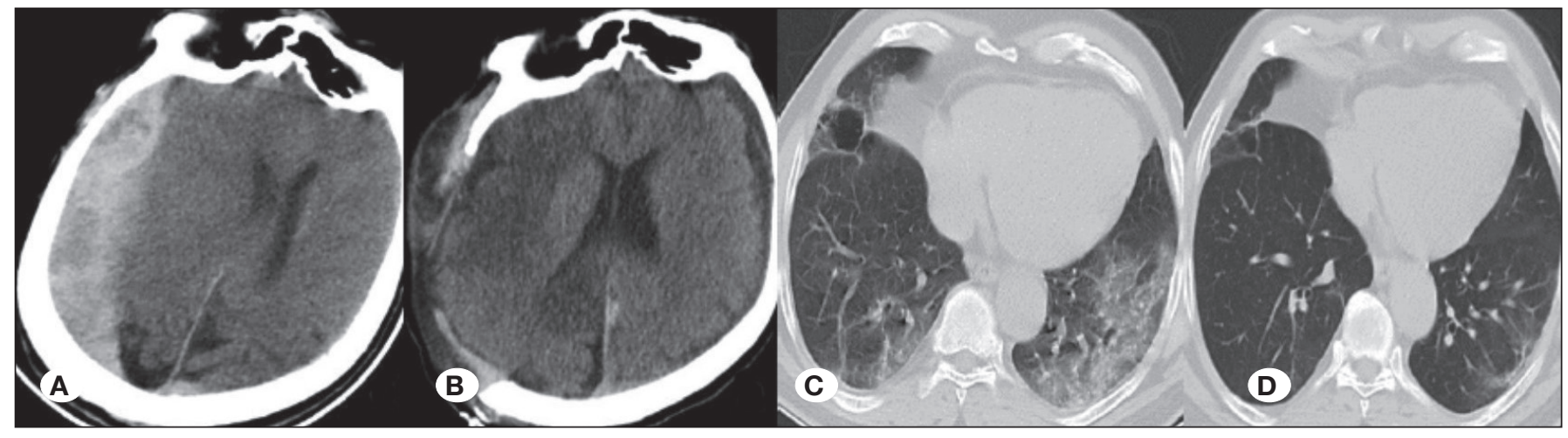

Figure 2: A) Preoperative cranial CT scan shows a right sided acute subdural hematoma -measuring $4 \mathrm{~cm}$ in its thickest part- compressing to the the right lateral ventricle and creating a midline shift of approximately $15 \mathrm{~mm}$. B) Postoperative cranial CT scan. Right parietal and temporal craniectomy was performed and right sided parietal-temporal subdural hematoma was evacuated. C) Chest CT scan shows ground glass-like density increases at the level of the posterobasal segment of the bilateral lungs and lower lobes and the lingular segment. D) $30^{\text {th }}$ day follow-up chest CT after medical treatment dor COVID-19; a decrease in ground glass appearance in the lung parenchyma is observed. 
Table II: Comparison of Patients and Hemorrhage Characteristics in Terms of Pneumonia, Mortality and Treatment

\begin{tabular}{|c|c|c|c|c|c|c|}
\hline & \multicolumn{2}{|c|}{ COVID 19 Pneumonia } & \multicolumn{2}{|r|}{ Mortality } & \multicolumn{2}{|c|}{$\begin{array}{c}\text { Treatment } \\
\text { (Surgery vs. Medical) }\end{array}$} \\
\hline & $\mathbf{p}$ & $95 \% \mathrm{Cl}$ & $\mathbf{p}$ & $95 \% \mathrm{Cl}$ & $\mathbf{p}$ & $95 \% \mathrm{CI}$ \\
\hline Age & 0.380 & $-12.455-4.805$ & 0.291 & $-14.582-4.482$ & 0.530 & $-14.180-7.469$ \\
\hline Gender & 0.153 & & 0.765 & & 0.123 & \\
\hline LMWH & 0.470 & & 0.529 & & 0.324 & \\
\hline Warfarin & 0.799 & & 0.982 & & 0.343 & \\
\hline ASA & 0.185 & & 0.081 & & 0.069 & \\
\hline Saturation & 0.690 & & 0.814 & & 0.858 & \\
\hline GCS & 0.002 & & 0.000 & & 0.758 & \\
\hline Motor loss & 0.454 & & 0.601 & & 0.418 & \\
\hline Mechanical Ventilation & 0.001 & & 0.000 & & 0.960 & \\
\hline INR & 0.810 & & 0.099 & & 0.427 & \\
\hline APTT & 0.826 & & 0.474 & & 0.473 & \\
\hline PTZ & 0.787 & & 0.144 & & 0.273 & \\
\hline Hemoglobin & 0.591 & $-1.3646-0.7824$ & 0.322 & $-.5921-1.7794$ & 0.302 & $-1.9269-0.6046$ \\
\hline Platelets & 0.135 & $-9397.390-68707.344$ & 0.038 & 2628.463-88114.394 & 0.571 & $-37461.810-66215.143$ \\
\hline CRP & 0.892 & & 0.398 & & 0.100 & \\
\hline Region of hemorrhage & 0.143 & & 0.426 & & 0.323 & \\
\hline Hemisphere & 0.141 & & 0.389 & & 0.672 & \\
\hline Type of Hemorrhage & 0.155 & & 0.263 & & 0.343 & \\
\hline Ventricular involvement & 0.003 & & 0.251 & & 0.750 & \\
\hline COVID-19 Pneumonia & - & & 0.073 & & 0.772 & \\
\hline Mortality & 0.073 & & - & & 0.066 & \\
\hline Treatment & 0.772 & & 0.066 & & - & \\
\hline
\end{tabular}

mortality group $(p=0.038)$. There was no difference between pneumonia and non-pneumonia patients in 30-day mortality $(p=0.073)$. Mortality was seen less often in the surgically treated group, but the difference was not significant $(p=0.066)$ (Table II). Mortality was found to be significantly higher in COVID-19 pneumonia patients with low $(\leq 8)$ GCS $(p=0.022)$, mechanical ventilation $(p=0.01)$ and low platelet counts $(p=0.039)$.

\section{Treatment (Medical vs. Surgery)}

There was no significant difference among $\mathrm{ICH}$ types in the treatment choice or existence of pneumonia $(p=0.343)$. Other clinical or laboratory characteristics did not affect the treatment choice in either the COVID-19 pneumonia group or all patients.

\section{ICH Type vs. Drugs}

There was no significant difference found between the types of $\mathrm{ICH}$ and antithrombotic drugs $(p=0.765)$.

\section{DISCUSSION}

Our study defined the characteristics of patients with $\mathrm{ICH}$ in terms of COVID-19 pneumonia, treatment, and mortality.

$\mathrm{ICH}$ is a disease with high mortality with an incidence of $0.9 \%$ in COVID-19 patients (31). In a study conducted with 125 patients in the United Kingdom, the prevalence rate of COVID-19 in ICH patients was found to be $12 \%$ (35). ICH accounts for $10-20 \%$ of all strokes, and its mortality is $33-52 \%$, which has been reported to be higher than that of ischemic stroke $(5,12,35)$. In our study, the mortality rate was $28.2 \%$ in total and $38.7 \%$ in patients with COVID-19 pneumonia.

In a systematic review, it was revealed that most of the $\mathrm{ICH}$ patients were male $(65.8 \%)$, which is similar to our study (56.4\%) (6). There were more patients under the age of 50 years $(23 \%)$ than in the literature (16\%) (6). The same study also showed that the most frequent type of $\mathrm{ICH}$ was IPH $(62.6 \%)$, which is compatible with our findings (59\%) (6). 
However, in another study including COVID-19 and ICH, the most frequently seen type of $\mathrm{ICH}$ was SAH (72.2\%).

We found that in our study, the patients were mostly admitted to the hospital with symptoms of loss of consciousness (32.1\%), followed by headache (15.4\%), syncope $(10.3 \%)$, motor loss (9\%), and seizure (9\%).

Medical or surgical treatments may be preferred in $\mathrm{ICH}$ treatments. Hematoma evacuation with different surgical methods and medical treatments has not provided a definite benefit $(24,38)$. Different clinical assessment criteria such as the Glasgow coma score (GCS) are used to identify brain injury and other neurological damage in trauma patients to determine the best therapy for patients $(14,33,37)$. In our study, the mortality rates of patients with a GCS of 8 or less were significantly higher than those of patients with a GCS $\geq 9$.

It has been reported that elevation of the inflammatory markers CRP and II-6 and D-dimer were detected (34). Although CRP levels were high in our study, they were not significant.

In a retrospective analysis of patients with cerebrovascular disease and COVID-19 pneumonia, ICH requiring surgical decompression was detected in 3 of 22 patients (34). The proportion of patients treated surgically was $23.1 \%$. A study conducted on intracranial hematoma patients reported that early hematoma evacuation did not affect three-month mortality (38). In our study, there was no difference between patients with and without pneumonia in terms of treatment. It may be considered that patient findings of COVID-19 pneumonia do not affect treatment. However, it was found that mechanical ventilation was more common in patients with lung involvement.

Nevertheless, the risks and mortality in patients with $\mathrm{ICH}$ and COVID-19 pneumonia requiring mechanical ventilation should be well evaluated in surgical treatments because of the complications occurring during and after intubation (4).

In our study, 52.6\% of ICH patients had findings of COVID-19 pneumonia on the thorax CT. The co-occurrence of COVID-19 and $\mathrm{ICH}$ can be found in the literature. Clinical studies have shown cerebral involvement that is due to COVID-19, and the virus was isolated in cerebrospinal fluid $(3,7,16,18,20)$. The COVID-19 virus causes cytokine storm syndrome $(19,23)$. This cytokine storm has been shown to disrupt the blood-brain barrier, causing demyelination without direct contact with the viral agent $(19,23)$. In these two different studies, cerebral damage that is due to COVID can occur as a result of both direct viral invasion and damage to the blood-brain barrier that is due to cytokine storms caused by the virus. In addition to pathophysiology, there are case series showing that hypoxia causes microvascular damage (7). Studies have shown that cytokine release and low platelet counts are also responsible for spontaneous ICH $(19,22)$. In our study, the platelet level was also found to be significantly lower in patients with $\mathrm{ICH}$ with pneumonia.

Antiplatelet therapy has been reported as a risk factor leading to high mortality in ICH patients (12). In our study, 37.2\% of our patients were using oral anticoagulants and antiplatelet therapy. Studies have shown that COVID-19 tends to cause thrombosis $(21,25,30)$. The incidence of thrombotic events was $31 \%$ in COVID-19 patients who were followed in the intensive care unit (17). Again, although it is thought that bleeding may be related to the hemorrhagic transformation of a multifocal ischemic cerebrovascular event or the use of anticoagulants (10), in our study, there was no significant difference in terms of anticoagulant or antiaggregant use in patients with or without COVID-19. Although their use causes bleeding, anticoagulants should be considered to prevent thrombotic complications of COVID-19, which may change mortality outcomes. In a retrospective study of 33 patients, anticoagulant use was found at a rate of $66.7 \%$ in $\mathrm{ICH}$ patients with a radiological diagnosis of COVID-19 (10). Again, there are cases of bleeding related to the use of prophylactic anticoagulants (13).

In a retrospective study, the $\mathrm{ICH}$ duration in 1 month was 11 days (27), $61 \%$ of these cases were SAH, and $33 \%$ were IPH. In our study, IPH was the most common form in patients with $\mathrm{ICH}$. ICHs can be seen as single or multifocal in different parts of the brain (36). In our study, intraparenchymal hemorrhage, one of the most common intracranial bleeding types, was mostly found in the frontal and right hemispheres. However, in patients with pneumonia, no significant difference was found between the types of bleeding or the involved hemispheres.

HT was found in $57.7 \%$ of the patients. In the literature, the most common comorbidity associated with cerebrovascular events has been reported as hypertension (31), and there are case reports of ICH without hypertension in COVID-19 cases (32). However, no relationship was found in terms of mortality in patients with pneumonia. In addition, ICH patients with low platelet counts were found to have high mortality rates. We think that $\mathrm{ICH}$ hemorrhages may predispose patients to the formation of intracranial hematomas that are due to brain damage caused by COVID-19, low platelet count, or high blood pressure.

In our study, while the malignancy rate was $17.9 \%$, in a study on hospitalized COVID-19 patients, the frequency of bleeding in the noncancerous COVID-19 group was found to be $20.8 \%$ (28).

During the COVID-19 pandemic, many patients admitted to the emergency department also affected the waiting, examination, and evaluation periods of the patients in the emergency service. Cowan and Trzeciak found a waiting time of 2.1-3.5 hours for patients in the United States emergency service, and $14 \%$ of the patients found that they waited in the emergency department for more than five hours (8). Henneman et al. found that patients wait 328 minutes in the emergency department and that patients who are discharged stay in the emergency department for 176 minutes (15). Although no studies compared the duration of the waiting time, in our study, we found that $60.3 \%$ of the $\mathrm{ICH}$ patients waited more than 6 hours, $35.9 \%$ waited $6-24$ hours, and $3.8 \%$ waited more than 24 hours in the emergency department. The hospitalization rate was $97.4 \%$. The waiting period is critical during the pandemic period. While $75.6 \%$ of the patients were discharged in $\leq 7$ days, the mortality rate was $28.2 \%$ during the 30 -day 
follow-up period. The high number of patients admitted to the emergency department, the insufficient number of intensive care and service beds, and the prolongation of referral times because of the density and occupancy of other health centers may have increased the emergency department's waiting times. Arrangements to be made for $\mathrm{ICH}$ patients diagnosed during the pandemic period may provide early surgical and medical treatment.

\section{Limitations}

Our study's most significant limitation is the small sample size, which did not make certain inferences on the choice of treatment. However, we designed a cohort study to take a picture of $\mathrm{ICH}$ patients with COVID-19 disease during the study period, and we hope to give readers some insight about the demographic and clinical characteristics of these patients. Second, according to the thorax CT findings, which were accepted as viral pneumonia with the RSNA, ACR, STR consensus, the time or stage of the pneumonia was not included in the analysis. Last, as we found no difference among the ICH types in terms of antithrombotic or antiaggregant drugs, we also did not underline their use because of the thrombotic effect of COVID-19. The study was conducted only on patients with $\mathrm{ICH}$, and further studies are required to examine bleeding in other systems.

\section{CONCLUSION}

Although it is unclear whether the relationship of cause and effect between COVID-19 and ICHs, and the treatment modalities or the existence of pneumonia did not affect ICH patient outcomes, it had an effect on the need for mechanical ventilation.

\section{REFERENCES}

1. Abzug MJ, Johnson SM: Catastrophic intracranial hemorrhage complicating perinatal viral infections. The Pediatric Infectious Disease Journal 19:556-559, 2000

2. Al-Hameed F: Spontaneous intracranial hemorrhage in a patient with Middle East respiratory syndrome corona virus. SMJ 38:196-200, 2017

3. Al-Olama M, Rashid A, Garozzo D: COVID-19-associated meningoencephalitis complicated with intracranial hemorrhage: A case report. Acta Neurochir 162:1495-1499, 2020

4. AHA/ASA Stroke Council Leadership: Temporary Emergency Guidance to US Stroke Centers During the Coronavirus Disease 2019 (COVID-19) Pandemic: On Behalf of the American Heart Association/American Stroke Association Stroke Council Leadership. Stroke 51:1910-1912, 2020

5. Benjamin EJ, Muntner P, Alonso A, Bittencourt MS, Callaway CW, Carson AP, Chamberlain AM, Chang AR, Cheng S, Das SR, Delling FN, Djousse L, Elkind MSV, Ferguson JF, Fornage M, Jordan LC, Khan SS, Kissela BM, Knutson KL, Kwan TW, Lackland DT, Lewis TT, Lichtman JH, Longenecker CT, Loop MS, Lutsey PL, Martin SS, Matsushita K, Moran AE, Mussolino ME, O'Flaherty M, Pandey A, Perak AM, Rosamond WD, Roth GA, Sampson UKA, Satou GM, Schroeder EB, Shah SH, Spartano NL, Stokes A, Tirschwell DL, Tsao CW, Turakhia MP,
VanWagner LB, Wilkins JT, Wong SS, Virani SS, On behalf of the American Heart Association Council on Epidemiology and Prevention Statistics Committee and Stroke Statistics Subcommittee: Heart disease and stroke statistics-2019 update: A report from the American Heart Association. Circulation 139(10):e56-e528, 2019

6. Cheruiyot I, Sehmi P, Ominde B, Bundi P, Mislani M, Ngure B, Olabu B, Ogeng'o JA: Intracranial hemorrhage in coronavirus disease 2019 (COVID-19) patients. Neurol Sci 42(1):25-33, 2021

7. Conklin J, Frosch MP, Mukerji S, Rapalino O, Maher MD, Schaefer PW, Lev MH, Gonzalez RG, Das S, Champion SN, Magdamo C, Sen P, Harrold K, Alabsi H, Normandin E, Shaw B, Sabeti PC, Branda JA, Brown EN, Westover MB, Huang SY, Edlow BL: Susceptibility-weighted imaging reveals cerebral microvascular injury in severe COVID-19. J Neurol Sci 421:117308, 2021

8. Cowan RM, Trzeciak S: Clinical review: Emergency department overcrowding and the potential impact on the critically ill. Critical Care 9:291-295, 2005

9. Do SS, Kay FU, Abbara S, Bhalla S, Chung JH, Chung M, Henry TS, Kanne JP, Kligerman S, Ko JP, Litt H: Radiological Society of North America Expert Consensus Statement on Reporting Chest CT Findings Related to COVID-19. Endorsed by the Society of Thoracic Radiology, the American College of Radiology, and RSNA. J Thorac Imaging 35(4):219-227, 2020

10. Dogra S, Jain R, Cao M, Bilaloglu S, Zagzag D, Hochman S, Lewis A, Melmed K, Hochman K, Horwitz L, Galetta S, Berger $\mathrm{J}$ : Hemorrhagic stroke and anticoagulation in COVID-19. J Stroke Cerebrovasc Dis 29:104984, 2020

11. Durand M, Sheehy O, Baril JG, LeLorier J, Tremblay CL: Risk of spontaneous intracranial hemorrhage in hiv-infected individuals: A population-based cohort study. J Stroke Cerebrovasc Dis 22:e34-e41, 2013

12. Garg R, Biller J: Recent advances in spontaneous intracerebral hemorrhage. F1000Res 8:302, 2019

13. Ghani MU, Kumar M, Ghani U, Sonia F, Abbas SA: Intracranial hemorrhage complicating anticoagulant prophylactic therapy in three hospitalized COVID-19 patients. J Neurovirol 26:602604,2020

14. Hemphill JC, Bonovich DC, Besmertis L, Manley GT, Johnston SC: The ICH score: A simple, reliable grading scale for intracerebral hemorrhage. Stroke 32:891-897, 2001

15. Henneman PL, Nathanson BH, Li H, Smithline HA, Blank FSJ, Santoro JP, Maynard AM, Provost DA, Henneman EA: Emergency department patients who stay more than 6 hours contribute to crowding. J Emerg Med 39:105-112, 2010

16. Jahanshahlu L, Rezaei N: Central nervous system involvement in COVID-19. Arch Med Res 51(7):721-722, 2020

17. Klok FA, Kruip MJHA, van der Meer NJM, Arbous MS, Gommers DAMPJ, Kant KM, Kaptein FHJ, van Paassen J, Stals MAM, Huisman MV, Endeman $\mathrm{H}$ : Incidence of thrombotic complications in critically ill ICU patients with COVID-19. Thrombosis Research 191:145-147, 2020

18. Krett JD: Hemorrhagic encephalopathy associated with COVID-19. J Neuroimmunol 2020 (Online ahead of print)

19. Mangalmurti N, Hunter CA: Cytokine storms: Understanding COVID-19. Immunity 53:19-25, 2020 
Berikol G. et al: Intracranial Hemorrhages and COVID-19 Pandemic

20. Mao L, Jin H, Wang M, Hu Y, Chen S, He Q, Chang J, Hong C, Zhou Y, Wang D, Miao X, Li Y, Hu B: Neurologic manifestations of hospitalized patients with coronavirus disease 2019 in Wuhan, China. JAMA Neurol 77(6):683-690, 2020

21. McFadyen JD, Stevens H, Peter K: The emerging threat of (Micro) Thrombosis in COVID-19 and its therapeutic implications. Circ Res 127:571-587, 2020

22. Md Noh MSF: COVID-19 and cerebral hemorrhage: Proposed mechanisms. J Neuroradiol 48(2):125,126, 2021

23. Mehta P, McAuley DF, Brown M, Sanchez E, Tattersall RS, Manson JJ: COVID-19: Consider cytokine storm syndromes and immunosuppression. The Lancet 395:1033-1034, 2020

24. Mendelow AD, Gregson BA, Rowan EN, Murray GD, Gholkar A, Mitchell PM: Early surgery versus initial conservative treatment in patients with spontaneous supratentorial lobar intracerebral haematomas (STICH II): A randomised trial. The Lancet 382:397-408, 2013

25. Miesbach W, Makris M: COVID-19: Coagulopathy, risk of thrombosis, and the rationale for anticoagulation. Clin Appl Thromb Hemost 26:107602962093814, 2020

26. Moinuddin A, McKinstry RC, Martin KA, Neil JJ: Intracranial hemorrhage progressing to porencephaly as a result of congenitally acquired cytomegalovirus infection? An illustrative report. Prenat Diagn 23:797-800, 2003

27. Nawabi J, Morotti A, Wildgruber M, Boulouis G, Kraehling H, Schlunk F, Can E, Kniep H, Thomalla G, Psychogios M, Hamm B, Fiehler J, Hanning U, Sporns P: Clinical and imaging characteristics in patients with SARS-CoV-2 infection and acute intracranial hemorrhage. J Clin Med 9(8):2543, 2020

28. Patell R, Bogue T, Bindal P, Koshy A, Merrill M, Aird WC, Bauer $\mathrm{KA}$, Zwicker Jl: Incidence of thrombosis and hemorrhage in hospitalized cancer patients with COVID-19. J Thromb Haemost 18(9):2349-2357, 2020

29. Poyiadji N, Shahin G, Noujaim D, Stone M, Patel S, Griffith B: COVID-19-associated acute hemorrhagic necrotizing encephalopathy: Imaging features. Radiology 296: E119-E120, 2020

30. Price LC, McCabe C, Garfield B, Wort SJ: Thrombosis and COVID-19 pneumonia: The clot thickens! Eur Respir J 56: 2001608, 2020

31. Rothstein A, Oldridge O, Schwennesen H, Do D, Cucchiara BL: Acute cerebrovascular events in hospitalized COVID-19 patients. Stroke 51(9):e219-e222, 2020

32. Sharifi-Razavi A, Karimi N, Rouhani N: COVID-19 and intracerebral haemorrhage: Causative or coincidental? New Microbes and New Infections 35:100669, 2020
33. Spetzler RF, Martin NA: A proposed grading system for arteriovenous malformations. J Neurosurg 65(4):476-483, 1986

34. Sweid A, Hammoud B, Bekelis K, Missios S, Tjoumakaris SI, Gooch MR, Herial NA, Zarzour H, Romo V, DePrince $\mathrm{M}$, Rosenwasser $\mathrm{RH}$, Jabbour $\mathrm{P}$ : Cerebral ischemic and hemorrhagic complications of coronavirus disease 2019. International Journal of Stroke 15(7):733-742, 2020

35. Varatharaj A, Thomas N, Ellul MA, Davies NWS, Pollak TA, Tenorio EL, Sultan M, Easton A, Breen G, Zandi M, Coles JP, Manji H, Al-Shahi Salman R, Menon DK, Nicholson TR, Benjamin LA, Carson A, Smith C, Turner MR, Solomon T, Kneen R, Pett SL, Galea I, Thomas RH, Michael BD, Allen C, Archibald N, Arkell J, Arthur-Farraj P, Baker M, Ball H, BradleyBarker V, Brown Z, Bruno S, Carey L, Carswell C, Chakrabarti A, Choulerton J, Daher M, Davies R, Di Marco Barros R, Dima S, Dunley R, Dutta D, Ellis R, Everitt A, Fady J, Fearon P, Fisniku L, Gbinigie I, Gemski A, Gillies E, Gkrania-Klotsas E, Grigg J, Hamdalla H, Hubbett J, Hunter N, Huys A-C, Ihmoda I, Ispoglou S, Jha A, Joussi R, Kalladka D, Khalifeh $H$, Kooij S, Kumar G, Kyaw S, Li L, Littleton E, Macleod M, Macleod MJ, Madigan B, Mahadasa V, Manoharan M, Marigold R, Marks I, Matthews P, Mccormick M, Mcinnes C, Metastasio A, Milburn-McNulty P, Mitchell C, Mitchell D, Morgans C, Morris $\mathrm{H}$, Morrow J, Mubarak Mohamed A, Mulvenna P, Murphy L, Namushi R, Newman E, Phillips W, Pinto A, Price DA, Proschel H, Quinn T, Ramsey D, Roffe C, Ross Russell A, Samarasekera N, Sawcer S, Sayed W, Sekaran L, Serra-Mestres J, Snowdon V, Strike G, Sun J, Tang C, Vrana M, Wade R, Wharton C, Wiblin L, Boubriak I, Herman K, Plant G: Neurological and neuropsychiatric complications of COVID-19 in 153 patients: A UK-wide surveillance study. The Lancet Psychiatry 7(10):875882,2020

36. Wee NK, Fan EB, Lee KCH, Chia YW, Lim TCC: CT fluidblood levels in COVID-19 intracranial hemorrhage. AJNR Am J Neuroradiol 41(9):E76-E77, 2020

37. Yu YL, Kumana CR, Lauder IJ, Cheung YK, Chan FL, Kou M, Chang CM, Cheung RT, Fong KY: Treatment of acute cerebral hemorrhage with intravenous glycerol. A double-blind, placebo-controlled, randomized trial. Stroke 23:967-971, 1992.

38. Zuccarello M, Brott T, Derex L, Kothari R, Sauerbeck L, Tew J, Van Loveren H, Yeh HS, Tomsick T, Pancioli A, Khoury $\mathrm{J}$, Broderick J: Early surgical treatment for supratentorial intracerebral hemorrhage: A randomized feasibility study. Stroke 30:1833-1839, 1999 